\title{
Technology-enabled activation of skin cancer screening for hematopoietic cell transplantation survivors and their primary care providers (TEACH)
}

Saro H. Armenian ${ }^{1 *}$, Lanie Lindenfeld ${ }^{1}$, Aleksi lukuridze ${ }^{1}$, Meagan Echevarria' ${ }^{1}$, Samantha Bebel ${ }^{1}$, Catherine Coleman ${ }^{2}$, Ryotaro Nakamura ${ }^{3}$, Farah Abdullah ${ }^{4}$, Badri Modi ${ }^{4}$, Kevin C. Oeffinger ${ }^{5}$, Karen M. Emmons ${ }^{6}$, Ashfaq A. Marghoob ${ }^{7}$ and Alan C. Geller ${ }^{6}$

\begin{abstract}
Background: Hematopoietic cell transplantation $(\mathrm{HCT})$ is a curative option for a growing number of patients with hematologic diseases and malignancies. However, HCT-related factors, such as total body irradiation used for conditioning, graft-versus-host disease, and prolonged exposure to immunosuppressive therapy, result in very high risk for melanoma and non-melanoma skin cancer (NMSC). In fact, skin cancer is the most common subsequent neoplasm in HCT survivors, tending to develop at a time when survivors' follow-up care has largely transitioned to the primary care setting. The goal of this study is to increase skin cancer screening rates among HCT survivors through patient-directed activation alone or in combination with physician-directed activation. The proposed intervention will identify facilitators of and barriers to risk-based screening in this population and help reduce the burden of cancer-related morbidity after HCT.
\end{abstract}

Methods/design: 720 HCT survivors will be enrolled in this 12-month randomized controlled trial. This study uses a comparative effectiveness design comparing (1) patient activation and education (PAE, $N=360$ ) including text messaging and print materials to encourage and motivate skin examinations; (2) PAE plus primary care physician activation (PAE + Phys, $\mathrm{N}=360$ ) adding print materials for the physician on the HCT survivors' increased risk of skin cancer and importance of conducting a full-body skin exam. Patients on the PAE + Phys arm will be further randomized 1:1 to the teledermoscopy (PAE + Phys+TD) adding physician receipt of a portable dermatoscope to upload images of suspect lesions for review by the study dermatologist and an online course with descriptions of dermoscopic images for skin cancers.

Discussion: When completed, this study will provide much-needed information regarding strategies to improve skin cancer detection in other high-risk (e.g. radiation-exposed) cancer survivor populations, and to facilitate screening and management of other late effects (e.g. cardiovascular, endocrine) in HCT survivors.

(Continued on next page)

* Correspondence: sarmenian@coh.org

'Department of Population Sciences, City of Hope, 1500, East Duarte Road, Duarte, CA 91010-3000, USA

Full list of author information is available at the end of the article

(c) The Author(s). 2020 Open Access This article is licensed under a Creative Commons Attribution 4.0 International License, which permits use, sharing, adaptation, distribution and reproduction in any medium or format, as long as you give appropriate credit to the original author(s) and the source, provide a link to the Creative Commons licence, and indicate if changes were made. The images or other third party material in this article are included in the article's Creative Commons licence, unless indicated otherwise in a credit line to the material. If material is not included in the article's Creative Commons licence and your intended use is not permitted by statutory regulation or exceeds the permitted use, you will need to obtain permission directly from the copyright holder. To view a copy of this licence, visit http://creativecommons.org/licenses/by/4.0/ The Creative Commons Public Domain Dedication waiver (http://creativecommons.org/publicdomain/zero/1.0/) applies to the data made available in this article, unless otherwise stated in a credit line to the data. 
(Continued from previous page)

Trial registration: ClinicalTrials.gov, NCT04358276. Registered 24 April 2020.

Keywords: Hematopoietic cell transplantation, Survivors, Skin cancer, Skin self-examination, Dermoscopy, Early detection, Patient activation

\section{Background}

\section{Melanoma/skin cancer in the general population}

Skin cancer, including melanoma and non-melanoma (NMSC), is diagnosed in 1 in 5 Americans during their lifetime and is the most common cause of cancer in the United States (U.S) [1]. Although the risk of dying from skin cancer is lower than many other cancers, the management of skin cancer is not without physical, psychological, and financial burden, with annual financial costs for patients alone estimated at more than $\$ 8$ billion per year [1]. The incidence of melanoma, the most commonly fatal type of skin cancer, continues to rise [2]; the true incidence of less-lethal NMSCs, such as basal cell carcinoma (BCC) and squamous cell carcinoma (SCC), is difficult to enumerate, as they are not tracked in national databases [2].

The Surgeon General wrote a Call to Action to Prevent Skin Cancer in 2014 [3], emphasizing skin cancer as a major public health concern. The U.S. Preventive Services Task Force (USPSTF) recently concluded that there was insufficient evidence to recommend screening for skin cancer in the general population, due to concern about potential harms, including the psychological stress of screening [4]. However, the USPSTF also emphasized that future research on skin cancer screening should focus on evaluating the effectiveness of targeted screening in people considered to be at higher risk for skin cancer, while measuring the possible benefits and harms of screening by both at-risk individuals and their providers [4].

\section{The high burden of health complications, including skin cancer, among HCT survivors}

Hematopoietic cell transplantation (HCT) is a curative option for a growing number of patients with hematologic diseases and malignancies. By the year 2030, there will be more than 500,000 HCT survivors in the U.S. [5] These survivors have been exposed to chemotherapy, other immunosuppressive therapy, and/ or radiation before $\mathrm{HCT}$ (for management of primary cancer), at time of HCT (for the transplant procedure), and after HCT (for graft-versus-host disease [GVHD] and/or relapse of primary cancer) $[5,6]$. Cumulative therapeutic exposures injure normal tissues, leading to premature onset of chronic health conditions such as subsequent cancers [6, 7]. We have shown that HCT survivors have a greater than 10-fold risk of developing subsequent cancers after HCT $[8,9]$, with skin cancer accounting for up to $60 \%$ of all subsequent solid cancers $[8,10]$. Treatment-related risk factors for skin cancer after HCT include radiation therapy (melanoma, BCC), chronic GVHD (SCC), length and severity of immunosuppression (SCC), and prolonged exposure to the antifungal voriconazole (SCC) [11-15]; it is estimated that > $80 \%$ of all HCT survivors will have at least one treatment-related risk factor for skin cancer [12]. In these survivors, the risk of melanoma is greater than five-fold higher (Hazard Ratio [HR]: 5.5, 95\% CI, 1.717.7) than in the general population [16], and the incidence of BCC and SCC exceeds $10 \%$ at 10 years after HCT $[11,16]$. The epidemiology of skin cancer in HCT survivors also differs from that of the general population, as survivors develop skin cancers at a younger age, present with advanced disease, and are more likely to have multiple recurrences, with a shorter latency between recurrences $[11,12,17,18]$. Due to anatomic location, some skin cancers are more visible to the patient, whereas others require discovery by a physician or family member, emphasizing the need for team-based approaches for monitoring and early detection of skin cancer in these individuals.

\section{The importance of skin examinations}

Because skin cancer and its precursors can be easily seen by the patient and caregivers, teaching skin selfexamination (SSE) and encouraging them to alert primary care physicians (PCPs) to skin changes is a key opportunity for health promotion. At-risk individuals (e.g. family history of skin cancer, prolonged sun exposure) should be encouraged to perform regular SSE (i.e. monthly) and should be educated as to the signs of suspicious pigmented lesions using the American Academy of Dermatology ABCDE (Asymmetry, Border, Color, Diameter, Evolution) algorithm [19]. Indeed, performing SSE may reduce mortality from melanoma by up to $63 \%$ [20]. Two studies in the general population provide the strongest evidence to date for the benefits of physician skin screening, showing $32 \%$ increased odds of having a smaller (i.e. more curable) melanoma at diagnosis following physician screening, and $40 \%$ reduction in melanoma mortality for physician-screened vs. unscreened individuals $[21,22]$. These studies highlight the efficacy of strategies that target both patient- and physiciandirected activation for optimal skin cancer screening, diagnosis, and management. 
Despite the unique risk factors and extremely high rates of skin cancer among HCT survivors, less than $20 \%$ of survivors report having performed SSE within the past 2 months and received a physician examination for skin cancer in the past year [23]. These low rates of screening are compounded by the inconsistent recommendations for skin cancer screening in HCT survivors by national guidelines (e.g. National Comprehensive Cancer Network [no specific guidelines], American Society for Transplantation and Cellular Therapy [routine self-skin examination encouraged] [24]). Spurred by the large gap between rates of disease and practice, a recent NIH-sponsored initiative called for studies to address barriers to risk-based cancer screening after HCT, recommending survivor- and physician-directed interventions to increase awareness and early detection of suspected cancers [25]. In response, our study team has already developed and tested materials to enhance the practice of thorough SSE in HCT survivors and to encourage physician activation; we will use these materials in the proposed study.

\section{Gaps in HCT survivorship care and the importance of patient activation}

We have shown that when long-term HCT survivors transition to PCPs, they no longer see their HCT physician on a regular basis, and rarely visit HCT survivorship care specialists [26, 27]. Thus, the long-term preventive care of HCT survivors is scattered across hundreds of thousands of individual PCPs. Although HCT survivors do seek primary care-more than $90 \%$ have seen their PCPs in the past two years-it is not in the cancer center context, where knowledge about the link between HCT-specific risk factors (e.g. radiation, GVHD) and skin cancer is more common [26, 27]. Therefore, it is of vital importance that HCT patients, who are at high risk of skin cancer, are trained to perform a thorough SSE and encouraged to ask their physician to conduct a thorough skin exam. Our research in the non-transplant setting indicates that PCPs are more likely to perform such exams when asked by patients to do so $[28,29]$.

Because skin cancer is the only cancer visible to the naked eye, photographs of suspect moles and lesions in print educational materials can boost recognition and practice of SSE [30]. Advances in technology, including the widespread availability of mobile phones and teledermoscopy (remote expert assessment of a photographed lesion) offer promising opportunities to improve early detection and treatment of skin cancer [31, 32]. The use of text messaging as an activation prompt is particularly appropriate because of the low cost, vast geographic coverage, and immediacy of this medium. In 2018, > 90\% of the US population owned a mobile phone (with negligible differences by sex, age, education) [33]. To date, three randomized dermatology-related interventions have used mobile phones. These studies have consistently shown that mobile phone-based text messaging can improve skin cancer prevention and detection behaviors (e.g. sunscreen application) and self-screening rates, with high user satisfaction [34-36]. To induce patient activation, we will therefore distribute printed SSE educational materials to participants, followed by a series of tailored text messages to complement the mailed printed materials.

\section{The importance of physician activation to implement skin cancer screening}

Although follow-up guidelines exist for HCT survivors, they do not explicitly state which provider (e.g. hematologist, PCP, other subspecialist) should manage which aspects of survivorship and preventive care. This lack of clarity for follow-up for survivors can result in under- or over-utilization of screening and diagnostic tests and add undue burden on the patient and care delivery system. These challenges are compounded by a lack of communication and coordination of care between oncology specialists and PCPs, as well as inadequate preparation of $\mathrm{PCPs}$ to deliver risk-based survivorship care [37]. These gaps in survivorship preventive care can be addressed through novel engagement strategies that bridge the gap between the specialized (e.g. HCT) providers and the PCPs who will ultimately be tasked with lifelong screening of at-risk survivors. Specific to this proposal, studies of PCPs have shown that they desire better training in dermatology and triaging cutaneous lesions, and that such training can be effectively provided across a variety of e-learning platforms [38, 39]. For the current proposal, we will build upon our past experiences with skin cancer screening studies in PCPs to deploy an HCT-focused e-learning module that informs PCPs about unique risk factors in HCT survivors and facilitates their completion of total body skin exams for these high-risk patients.

\section{Patient activation model}

Our proposed survivor-directed intervention will be guided by the Patient Activation Model, which posits that an activated patient is better prepared to participate in self-management activities [40-43]. Patient activation is increasingly seen as central to achieving improved quality of care, better health outcomes, and less-costly health care utilization [42]. Patient activation involves four stages: 1) believing that taking an active role as a patient is important, 2) having the confidence and knowledge necessary to take action, 3) taking action to maintain and improve one's health, and 4) staying the course even under stress [40]. The significance of patient 
activation has been recognized in ongoing health care reform efforts, including by the Center for Medicare and Medicaid Innovation [41, 42]. Since 2004, a number of studies have shown patient activation to be related to healthy behaviors (e.g. physical activity, healthy diet), appropriate use of the health care system (e.g. having a regular and timely source of care), and chronic care selfmanagement (e.g. keeping a diary of blood pressure readings) [43-45]. Additional evidence suggests that PCPs likely play an important role in increasing patient activation. For example, one study found that PCPs who helped their patients in very concrete and specific ways (e.g. learning to monitor their condition, setting goals), had greater numbers of activated patients than those who did not [46]. Further, a checklist brought by a patient to a routine visit can serve as an activation tool for a provider and has been shown to encourage a PCP to: examine the patient's skin, make a referral if necessary, motivate the patient to conduct SSE, record the high-risk status of the patient, and make early detection practices routine in subsequent visits [47]. As such, we will integrate a checklist as part of our patient-directed intervention.

\section{Physician-directed intervention}

Our proposed physician-directed intervention is informed by the established patterns of long-term followup care after HCT $[23,26,27]$, whereby a patient is transitioned from specialized cancer centers to the community, following stabilization of the patient's acute medical needs. In this context, the community-based SharedCare Model [37] allows optimal coordination between the HCT physician and other physician groups providing care. Simply stated, shared care refers to the care of a patient that is shared by two or more different specialties (or systems that are separated by some boundaries). The Shared-Care Model has been demonstrated to improve patient outcomes and enhance the management of patients with various chronic diseases including diabetes [48] and chronic renal disease [49], as well as those receiving oral anticoagulant therapy [50]. The cornerstone of shared care is communication and a period of transfer of knowledge between the specialist (e.g. oncologist/ HCT physician) and the PCP.

\section{Leveraging technology to facilitate follow-up of abnormal findings}

For many patients and PCPs, lack of access to expert examinations and long wait times to see a dermatologist hinder/delay diagnosis and preclude treatment of earlystage skin cancers. A national survey of dermatologists found mean wait times for patients with an urgent changing mole was 38 days (range: 20-73) [51]. Teledermoscopy (TD) leverages the power of technology to enable clinicians to interact with dermatologists remotely, in less time. Acquiring dermoscopic images of lesions using a special magnifying lens allows key details of lesions to be transmitted to a dermatologist in real time (Fig. 1) [32]. We have shown that TD can improve the sensitivity and specificity of skin cancer detection by PCPs, and can identify smaller-diameter BCC, nearly all of which can be treated by PCPs using shave biopsy or the topical agent imiquimod, rather than the invasive surgical procedures required to treat larger lesions by a dermatologist [52]. As of 2018, there were $>60$ TD centers in the US [53]; given the continued rapid expansion of technology and the emphasis on improving quality of care, the presence of TD in the US will likely continue to grow. For the current study, we will rely on well-established TD platforms that are rapidly scalable for the primary care setting, allowing for timely identification and referral of suspect lesions.

\section{Methods/design}

In this randomized controlled trial, we will prospectively enroll $720 \mathrm{HCT}$ patients over a three-year period, and will use a comparative effectiveness design (Fig. 2) comparing: patient activation and education (PAE, $N=360$ ), which consists of patient-directed print materials and text messaging (12 messages over a $9 \mathrm{~m}$ period) vs. $P A E$ plus physician activation (PAE + Phys, $\mathrm{N}=360$ ), which also includes physician-directed activation/educational materials about: 1) survivors' increased skin cancer risk; 2) the benefits of and the skills needed to conduct fullbody skin exams; and 3) the importance of recommending routine SSE to patients. Among the 360 survivors assigned to PAE + Phys, we will further randomize (1:1) the PCPs to receive either printed physician activation materials $(N=180)$ or printed physician activation materials plus an e-learning module with access to TD (PAE + Phys+TD; $\mathrm{N}=180)$, which includes provision of a dermoscopic lens to take photographs of suspect

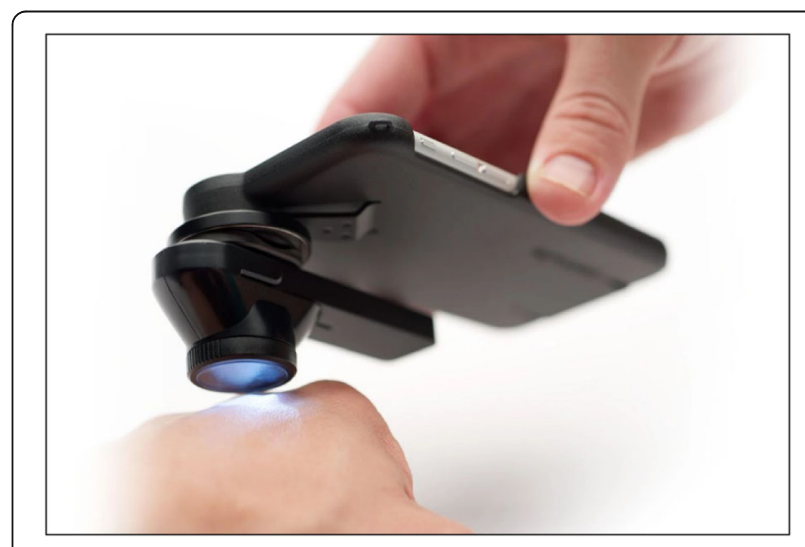

Fig. 1 DermLite Dermatoscope. DermLite (www.dermlite.com) works with virtually any smartphone and tablet 


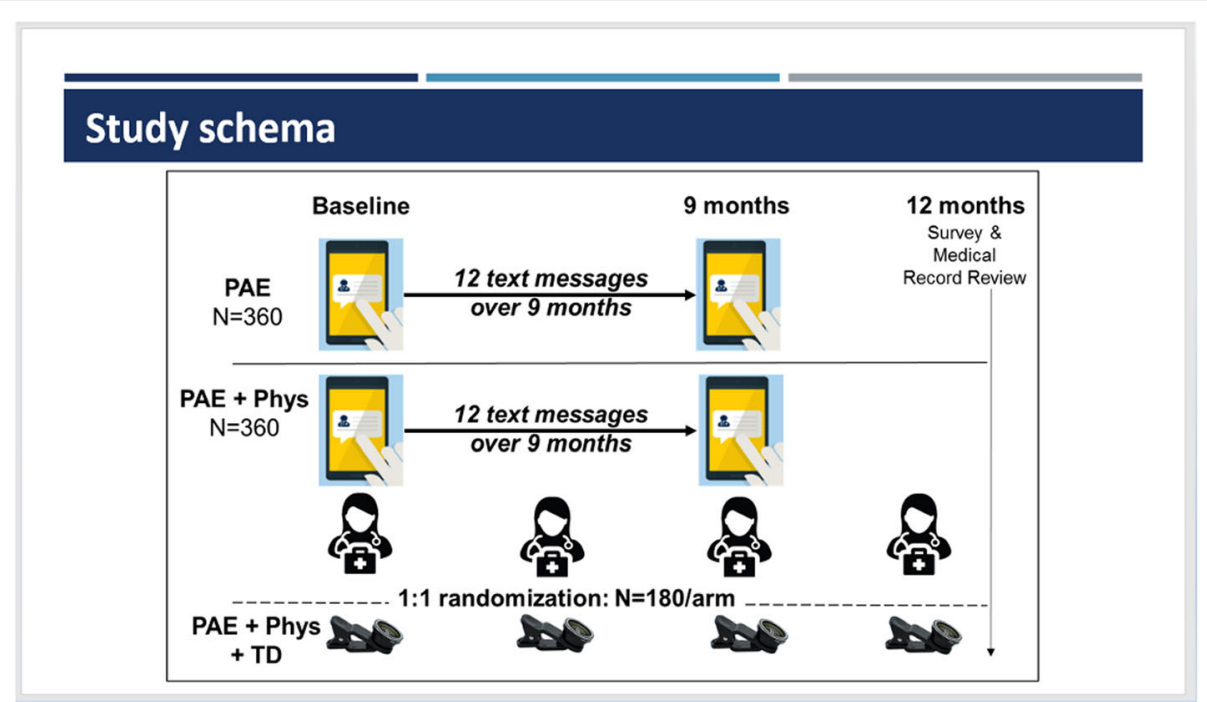

Fig. 2 Study Schema for different arms. PAE: Patient Activation/Education (educational materials and text messages). PAE + Phys: Patient Activation/Education (educational materials and text messages) + physician activation/educational materials targeted to identified primary care providers (PCPs). PAE + Phys+TD: Phys: Patient Activation/Education (print materials and text messages) + physician activation/education + teledermoscopy (PCPs receive a dermatoscope to upload images of suspicious skin lesions to the remote study dermatologist)

lesions for review by the teledermatologist and recommendations and action steps needed to obtain expedited care for his/her patient. Participants and physicians will take part in the study for $12 \mathrm{~m}$, with efficacy and endpoint assessments at the $12 \mathrm{~m}$ follow-up.

Inclusion requirements are as follows: have undergone autologous or allogeneic $\mathrm{HCT}$ at $\mathrm{COH}$; are 1 to 5 years after HCT; $\geq 18$ years of age at the time of enrollment; have seen a PCP in the previous $12 \mathrm{~m}$ or planning to do so in next $12 \mathrm{~m}$; have a mobile phone with the ability to receive text messages; are able to read and write in English or Spanish; and are able to provide informed consent. Exclusion criteria are as follows: have no evidence of active hematologic malignancy or acute illness that would limit study participation.

\section{Participants and randomization}

Eligible patients will be identified and recruited at $\mathrm{COH}$ from existing databases and physician referrals. Study staff will pre-screen everyone by reviewing the medical charts and will exclude anyone with conditions or reasons that may prohibit study entry. Participants who meet study eligibility criteria will be invited to enroll. All participants are enrolled on the study once they provided written consent and all eligibility requirements for the study have been met.

Participants are randomized 1:1 to PAE or PAE + Phys using a blocked stratified randomization. Stratification factors will include age $(<50, \geq 50$ years), sex (male, female), HCT type (autologous, allogeneic), and race/ethnicity (white, other). Participants randomized to PAE + Phys $(N=360)$ will be further randomized 1:1 to the
PAE + Phy + TD arm, which includes the addition of an e-learning web-based skin cancer screening module with TD $(N=180)$ versus print materials alone $(\mathrm{N}=180)$. To ensure that enrolled participants reflect the demographics of all eligible patients, we will stratify recruitment by age $(+/-5 y)$, sex, race/ethnicity, and HCT type (autologous/allogeneic). The current study has been approved by the Institutional Review Board of City of Hope (approval number: IRB \#20096).

\section{Patient-directed intervention}

All participants receive a study packet in either English or Spanish that includes: a personalized letter from the $\mathrm{COH}$ team welcoming them to the study; print materials about their skin cancer risk (highlighting HCT-specific risk factors), instructions on how to conduct SSE, pictures of worrisome lesions, an appointment checklist, and a checklist to help them maximize the effective of their physician skin examinations. Participants will then receive 12 separate text messages (once every 3 weeks) throughout the $9 \mathrm{~m}$ period designed to encourage them to:

- Thoroughly examine their skin using the instructional pictorial diagrams and photographs of abnormal lesions provided in the print materials;

- Request physician skin exams and bring the checklist to their PCP; and

- Develop a collaborative care plan (between the PCP and participant) including common responsibility for monitoring and quickly following up on new and changing moles and lesions. 
The specific patient baseline and $12 \mathrm{~m}$ measures are summarized in Table 1 . To optimize patient participation, we will employ proven strategies that include:

- Providing electronic and paper questionnaire options,

- Offering incentives ( $\$ 40 /$ set of completed questionnaires, baseline and $12 \mathrm{~m}$ ), and

- Sending mailed reminder notices and text messages ahead of the $12 \mathrm{~m}$ questionnaire.

\section{Physician-directed intervention}

At study enrollment, participants will be asked to provide the name and contact information of their PCP and ideally the date of their next PCP visit. The physicians of patients randomized to PAE + Phys will receive a packet consisting of:

- A letter that describes the intervention and encourages them to do a full-body skin examination at the patient's next visit and to recommend that the patient performs SSE;

- Information about HCT survivors' increased risk of skin cancer;

- Images of suspect moles and lesions; and

- Instructions on how to perform a full-body skin examination.

Per the Shared-Care Model of Survivorship Care, the top sheet of the packet will include a personalized letter by from the patient's HCT physician reminding the PCP about the risk of skin cancer among HCT patients and encouraging them to screen for suspicious moles and lesions. We will send the physician activation materials approximately 7 days after patient enrollment and a reminder letter approximately 10 days before the patient visit. This approach ensures that physicians have the activation materials in case they receive participant inquiries prior to the scheduled appointment.
Physicians of patients randomized to PAE + Phys+TD will receive the same educational materials as PAE + Phys. In addition, they will receive a free portable dermatoscope with instructions for uploading images of suspect lesions. The dermatoscope can be attached to smartphones and tablets and allows for high-quality visualization of subsurface skin structures that are not usually visible to the naked eye. Advantages of this technology are that it can facilitate detection of skin cancers in the early stages of development. Physicians in the PAE + Phys +TD will also be asked to view an online module that will provide clear instructions for using a dermatoscope, and steps to integrate dermoscopy into their practice. Physicians will be strongly encouraged to take pictures of lesions of patients for whom they have a low to moderate level of concern of malignancy. The study dermatologist will review all dermoscopic images and provide written feedback to PCPs within approximately one week. Report outcomes will range from:

- Image of insufficient quality, photograph needs to be re-taken, with instructions on how to improve resolution;

- Image of sufficient quality-benign;

- Image of sufficient quality-benign, but final management decision will rest on re-evaluating a repeat image taken four weeks later; and

- Image of sufficient quality-lesion of concern and participant instructed to see a dermatologist.

We expect that teledermoscopy reports revealing positive findings will spur physicians and patients to obtain expedited follow-up care, including speedier referrals to dermatologists, thereby reducing wait times.

\section{Statistical considerations}

We will test our first hypothesis that compared to PAE, participants randomized to PAE + Phys will report higher rates of thorough SSE and physician skin exam.

Table 1 Measures and definitions

\begin{tabular}{|c|c|}
\hline MEASURE & Definition \\
\hline SKIn SELF-Examination (SSE) & $\begin{array}{l}\text { Defined as performing at least one SSE during the } 2 \mathrm{~m} \text { prior to the baseline and } 12 \mathrm{~m} \text { follow-up assessments [54-56]. } \\
\text { Additionally, survivors will be asked how often in the prior } 2 \mathrm{~m} \text { they had thoroughly examined each of eight areas of } \\
\text { the body ("the front of you from the waist up," "the front of your thighs and legs," "the bottom of your feet," "your } \\
\text { calves," "the backs of your thighs," "your buttocks and lower parts of your back," "your upper back," and "your scalp.") This } \\
\text { serves as a measure of quality of each patient's report of the SSE. }\end{array}$ \\
\hline PhySICIAN SKIN EXAM & $\begin{array}{l}\text { The physician skin exam will be based on response to the question, "During the past } 12 \text { months, has a doctor } \\
\text { deliberately checked all or nearly all of your whole body for the early signs of skin cancer?" We will ask about the extent } \\
\text { of the examination ("Did it include the lower back? [...] The scalp?") and whether the participant was completely } \\
\text { undressed for any part of the examination [54-56]. Patients will be asked whether the examination took place during a } \\
\text { scheduled visit or was prompted by the participant's finding of a new lesion }\end{array}$ \\
\hline $\begin{array}{l}\text { Skin CANCER Detection } \\
\text { KNOWLEDGe }\end{array}$ & $\begin{array}{l}\text { Skin Cancer Detection Knowledge will be assessed using an established questionnaire on skin cancer risk factors (e.g. } \\
\text { skin phototype, family history of skin cancer) [57]. }\end{array}$ \\
\hline
\end{tabular}


We will administer patient questionnaires at baseline and $12 \mathrm{~m}$ to ask about skin examinations performed within the past 12 months. We will generate a binary outcome (Y) based on patient responses from the $12 \mathrm{~m}$ end-of-study questionnaire, whereby $\mathrm{Y}=1$ if they report having conducted a SSE and having received a physician skin examination. All other responses will be considered $\mathrm{Y}=0$. Due to randomization, we do not expect differences in baseline patient and treatment characteristics between the two study arms. Nevertheless, we will compare baseline characteristics (e.g. age, sex, race/ethnicity, diagnosis, type of $\mathrm{HCT}$, radiation exposure, severity and extent of GVHD) of the two groups using standard univariate analyses. To determine the efficacy of the intervention, we will conduct intention-to-treat analysis. We will compare the proportion of patients who report having conducted an SSE and had a physician exam during the 2 $\mathrm{m}$ prior to the $12 \mathrm{~m}$ follow-up assessment, using Chisquared analysis. We will use logistic regression to adjust for imbalance in patient characteristics and risk factors. We will also test for group by covariate interactions, depending on group main effect. Per the ASK trial [58], we anticipate the proportion $(p)$ of patients who report SSE and a physician exam during the $2 \mathrm{~m}$ prior to the $12 \mathrm{~m}$ follow-up assessment in the PAE arm to be $40 \%$.

Assuming a Type I error $=5 \%, 270$ patients per arm at month 12 (accounting for 25\% attrition from baseline) will provide $80 \%$ power to detect a minimum percentage point difference of $12 \%$ or an odds ratio of 1.62 between the two study arms (Table 2). Our previous experience with patient- and $\mathrm{PCP}$-directed interventions suggests that a $12 \%$ difference is a conservative estimate and achievable for the current study.

In addition, we will test our second hypothesis that compared to PAE, participants randomized to PAE + Phys will report shorter time to definitive diagnosis of suspect lesions. From data reported on the patient's 12month questionnaire, we will determine the time interval between a participant's first notice of a suspect mole or lesion and the date on which a definitive diagnosis was made (i.e. by the PCP or a dermatologist). The outcome will be a continuous variable and we will employ a generalized linear model (GLM) to compare the interval between the two study arms, adjusted for covariates of interest. We will begin with bivariate models to determine potential variables to include in a multivariable

Table 2 Projected proportions of patients who will report SSE and PCP exam at $12 \mathrm{~m}$ (PAE vs. PAE + Phys)

\begin{tabular}{llll}
\hline PAE (proportion [p1]) & $40 \%$ & $40 \%$ & $40 \%$ \\
PAE + Phys (p2) & $52 \%$ & $55 \%$ & $60 \%$ \\
Odds ratio & 1.62 & 1.83 & 2.25 \\
Number (per arm) & 270 & 173 & 97 \\
\hline
\end{tabular}

regression model. If the group main effect is significant, interactions of the group main effect with other variables will be examined. Power calculation: We will assume that 10 to $30 \%$ of patients will have a concerning mole or lesion for which they will seek care from their PCP or a dermatologist during the study period [12, 59, 60]. Mean wait time (time between call for appointment and definitive diagnosis by their PCP or a dermatologist, if equivocal) was assumed to be 30 days [51], with a range of standard deviations ( $\mathrm{SD}=5$ to 15 ). Based on these values, we will have $80 \%$ power at Type I error $=5 \%$ to detect a significant group difference ranging from 1.9 days $(\mathrm{SD}=5)$ to 5.7 days $(\mathrm{SD}=15)$ if $30 \%$ of participants seek follow-up care; or 3.3 days $(\mathrm{SD}=5)$ to 10.0 days $(\mathrm{SD}=15)$ if only $10 \%$ of participants seek care for a concerning mole or lesion by $12 \mathrm{~m}$ (Table 3 ).

Finally, we will test our hypothesis that PCPs randomized to PAE + Phys+TD will have greater recognition of suspect lesions and more appropriate as well as costeffective referral patterns compared to PAE + Phys alone. We will administer questionnaires at baseline and $12 \mathrm{~m}$ to all PCPs of participating patients to assess their ability to recognize suspect lesions and their self-confidence in performing the skin cancer exam and making referrals. We will compare the group difference in changes in attitude over time, using GEE for normally distributed data, with a compound symmetry covariance matrix analysis to account for within-physician correlation. We will dichotomize the Likert scale [1-5] response and compare the proportion of PCPs reporting a higher $(\geq 4$ vs. $<$ 4) level of confidence at $12 \mathrm{~m}$ compared to baseline between groups, using the longitudinal binomial GEE model with a compound symmetry covariance structure. Covariate adjustment will be made in these models as necessary. Power Calculation: With 180 PCPs per arm at baseline and 135 at $12 \mathrm{~m}$, assuming a Type I error $=5 \%$, we will have $80 \%$ power to detect odds ratios ranging

Table 3 Detectable difference in time to definitive diagnosis between arms, given a range of proportions (patients with concerning lesions), and standard deviations (SD) around mean time

\begin{tabular}{lll}
\hline Proportions & SD & Group Difference \\
\hline $10 \%$ & 5 & 3.3 \\
& 10 & 6.7 \\
& 15 & 10 \\
$20 \%$ & 5 & 2.4 \\
& 10 & 4.7 \\
& 15 & 7.1 \\
$30 \%$ & 5 & 1.9 \\
& 10 & 3.8 \\
& 15 & 5.7 \\
\hline
\end{tabular}


from 2.7 to 4.0 (corresponding to absolute differences: $20-30 \%)$ at $12 \mathrm{~m}$, given a participation rate range of $50-70 \%$.

\section{Sample size calculations}

We will approach approximately 850 potentially eligible patients for enrollment; we anticipate 720 (85\%) patients will consent and be randomized (360/ arm) at baseline, and 540 (75\% retention) will be evaluable at $12 \mathrm{~m}$ (270/arm).

\section{Economic impact measures}

To determine intervention cost estimates, we will include both the cost of intervention components as well as the cost of implementing the intervention. Intervention component costs include print materials and mailing, text messages, dermatoscope, and personnel time. Time spent developing materials will not be included, as these are fixed, and would not be incurred if another site adopts the intervention. We will value commercially available items, such as dermatoscopes, at their average retail price rather than the subsidized rate provided specifically for this study. We will collect information for estimating intervention costs from study records and personnel reports. We will value personnel time at prevailing national average wage rates for the relevant occupational categories and explore alternative values in sensitivity analysis.

To estimate the economic impact of the intervention, we will survey patients at the $12 \mathrm{~m}$ assessment regarding their use of specific health care services. They will be asked about visits with PCPs and dermatologists, receipt of relevant diagnostic procedures including biopsies and imaging, and treatment for any newly diagnosed skin conditions. Each health care service will be multiplied by a unit cost amount in order to estimate total costs per participant. We will use Medicare's Direct Practice Expense and Resource-Based Relative Value Scale to estimate average unit costs for physician and laboratory services. Although some study participants will not be Medicare beneficiaries, Medicare's reimbursement methodology was developed to reflect true resource costs. For this reason, Medicare reimbursement may be used as a proxy for unit cost, even when the population of interest is not limited to Medicare beneficiaries. This methodology has been employed in economic analyses of other cancer screening interventions. In sensitivity analysis, we will evaluate a range of unit cost estimates [61, 62].

Our assessment of the downstream costs of the intervention, as well as the cost of the intervention itself, will allow us to perform a limited cost-effectiveness analysis. Specifically, we will estimate the cost per additional SSE completed and the cost per additional PCP exam completed, comparing the two intervention arms. Given that the primary focus of the trial on non-economic endpoints and the associated sample size requirements, we will not conduct formal hypothesis testing on the economic outcomes. The economic impact of the intervention will be evaluated using standard incremental cost-effectiveness analysis methods, and sensitivity analysis will be used to assess the impact of assumptions and uncertainty on results and conclusions. Although estimation of lifetime costs and outcomes associated with the study interventions are beyond the scope of this proposal, results of the cost analyses will serve as preliminary data for future interventions that explore the longterm cost-effectiveness of increasing skin cancer screening among HCT survivors.

\section{Discussion}

A key factor to consider when developing any preventive health intervention is sustainability, and the likelihood of dissemination outside of the research setting should the intervention be found effective (scalability). Health care settings, in particular, pose real challenges to implementation of behavioral interventions, due to the time and skills needed for implementation. Interactive technologies based on evidence-based behavior change principles can begin to address barriers to implementation of behavior change programs in health care.

These technology-enabled interventions can ensure that a consistent, high-quality message is delivered to patients, can inform patient-provider interactions, and can maximize staffing efficiencies; they can also address a wide variety of behaviors simultaneously. Thus, interactive technology can provide a streamlined, consistent method for conducting many aspects of evidence-based behavior change counseling. Randomized controlled studies have demonstrated that use of interactive technologies does support lifestyle behavior change in patients.

Studies of PCPs have shown that they desire better training in dermatology and triaging cutaneous lesions, and that such training can be effectively provided across a variety of e-learning and technology-enabled platforms. We have designed this intervention with careful consideration of how it might be sustained outside of the research context. Delivery of the PAE intervention can easily be integrated into HCT care, as it is routine to provide patients with written or electronic materials related to ongoing care. If the intervention is effective, we envision working with national organizations (e.g. American Cancer Society; American Society for Transplantation and Cellular Therapy) to determine the best strategies for dissemination to HCT programs throughout the country.

\section{Conclusion}

HCT survivors have been exposed to cumulative therapeutic exposures that injure normal tissues, leading to premature onset of chronic health conditions such as 
subsequent cancers [6, 7]. HCT survivors have a $>10$ fold risk of developing subsequent cancers after HCT [8, 9], with skin cancer accounting for up to $60 \%$ of all subsequent solid cancers $[8,10]$. Importantly, the epidemiology of skin cancer in HCT survivors differs from that of the general population, as survivors develop skin cancers at a younger age, present with advanced disease, and are more likely to have multiple recurrences, with a shorter latency between recurrences [11, 12, 17, 18]. Despite the unique risk factors and extremely high rates of skin cancer among HCT survivors, less than $20 \%$ of survivors report having performed skin self-exam (SSE) within the past 2 months and received a physician examination for skin cancer in the past year [23].

In HCT survivors, skin cancers develop at a time when their follow-up has largely transitioned to the primary care setting [12], emphasizing the need to develop innovative strategies that educate survivors and PCPs alike to improve skin cancer self-examination and clinical screening rates. Thus, we have developed a $12 \mathrm{~m}$ intervention focused on early detection of skin cancer and timely medical follow up among HCT survivors. Findings from this study can 1) establish the efficacy of PAE, and the relative benefit of physician activation; 2) inform the practice of skin cancer screening using innovative strategies that are readily applicable in the clinical setting; and 3) identify facilitators of and barriers to appropriate delivery of survivorship care in long-term HCT survivors. It is anticipated that results obtained from this intervention can potentially help develop strategies to facilitate the screening and management of other late effects (e.g. cardiovascular, endocrine) in HCT survivors, and to improve skin examination vigilance and skin cancer detection in other high-risk (e.g. radiation-exposed) cancer survivor populations. Given the emerging interest in remote patient monitoring and healthcare delivery due global crises such as the COVID-19 pandemic, it is especially timely to consider new paradigms to address the needs of cancer survivors.

\section{Trial status}

Study enrollment has not commenced.

\footnotetext{
Abbreviations

ABCDE: Asymmetry, Border, Color, Diameter, Evolution; BCC: Basal cell carcinoma; $\mathrm{COH}$ : City of Hope; GVHD: Graft-versus-host disease; HCT: Hematopoietic cell transplantation; ICF: Informed consent form; m: month; NMSC: Non-melanoma skin cancer; PAE: Patient activation and education; PAE + Phys: Patient activation and education plus physician activation; PAE + Phys+TD: PAE + Phys plus e-learning web-based skin cancer screening module with teledermoscopy; PCP: Primary care physician; SCC: Squamous cell carcinoma; SD: Standard deviation; SSE: Skin selfexamination; TD: Teledermoscopy; US: United States; USPSTF: U.S. Preventative Services Task Force
}

\section{Acknowledgements}

The authors would like to thank the patients and families for their participation in this study.

\section{Authors' contributions}

SHA: principal investigator, study concept and design, manuscript preparation, review and revision; LL: study coordination, manuscript preparation, review and revision; Al: study coordination, manuscript review and revision; ME: study coordination, manuscript review and revision; CC: coordinated and led development of intervention materials; KCO: study concept and design, manuscript review and revision; KME: study concept and design, manuscript review and revision; RA study concept and design, manuscript review and revision; FA: study concept and design, manuscript review and revision BM: study concept and design, manuscript review and revision SB: manuscript review and revision, AAM: study dermatologist, manuscript review and revision; ACG: co-principal investigator, study concept and design, manuscript review and revision. All authors have read and approved the final version of this manuscript. All authors have approved the submitted version and have agreed both to be personally accountable for the author's own contributions and to ensure that questions related to the accuracy or integrity of any part of the work, even ones in which the author was not personally involved, are appropriately investigated, resolved, and the resolution documented in the literature.

\section{Authors' information}

Not applicable.

\section{Funding}

This study is supported by the National Institutes of Health/National Cancer Institute (NIH/NCl) under Award Number R01CA249460 (Pls: Armenian, Geller). Funding for this trial covers salaries and wages (years 1-5); fringe benefits (years 1-5); personnel costs (years 1-5); materials and supplies (years 2-4); travel for meetings (years 1-5) facilities and administrative costs (years 1-5); and publication costs (year 5). A seed grant (Safer family) is available for any unforeseen administrative costs. The content is solely the responsibility of the authors and does not necessarily represent the official view of the $\mathrm{NIH}$ or Safer family.

\section{Availability of data and materials}

Study enrollment has not yet commenced; thus, there is no available data or materials.

\section{Ethics approval and consent to participate}

The protocol, City of Hope informed consent forms, participant education and recruitment materials, and other requested documents have been reviewed and approved by the City of Hope Institutional Review Board with respect to scientific content and compliance with applicable research and human subjects' regulations. Subsequent to initial review and approval, City of Hope's Institutional Review Boards will review the protocol at least annually.

\section{Consent for publication}

Not applicable as study enrollment has not commenced.

\section{Competing interests}

There is no competing interest to declare on the part of any named author.

\section{Author details}

'Department of Population Sciences, City of Hope, 1500, East Duarte Road, Duarte, CA 91010-3000, USA. ²Department of Population Sciences, Dana-Farber Cancer Institute, Boston, MA, USA. ${ }^{3}$ Department of Hematology \& Hematopoietic Cell Transplantation, City of Hope, Duarte, CA, USA. ${ }^{4}$ Department of Surgery, City of Hope, Duarte, CA, USA. ${ }^{5}$ Department of Medicine, Community and Family Medicine and Population Health Sciences, Duke Cancer Institution, Duke, North Carolina, USA. ${ }^{6}$ Department of Social and Behavioral Sciences, Harvard TH Chan School of Public Health, Boston, MA, USA. 'Department of Dermatology, Memorial-Sloan Kettering Cancer Center, New York, NY, USA.

Received: 22 June 2020 Accepted: 28 July 2020

Published online: 03 August 2020

\section{References}

1. The Skin Cancer Foundation. https://www.skincancer.org/skin-cancerinformation/skin-cancer-facts. Accessed 19 June 2019. 
2. Guy GP Jr, Machlin SR, Ekwueme DU, et al. Prevalence and costs of skin cancer treatment in the U.S., 2002-2006 and 2007-2011. Am J Prev Med. 2015;48:183-7.

3. The Surgeon General's Call to Action to Prevent Skin Cancer 2014. https:// www.surgeongeneral.gov/library/calls/prevent-skin-cancer/index.html. Accessed 19 June 2019.

4. Wernli KJ, Henrikson NB, Morrison CC, et al. Screening for skin Cancer in adults: updated evidence report and systematic review for the US preventive services task force. JAMA. 2016;316:436-47.

5. Majhail NS, Tao L, Bredeson C, et al. Prevalence of hematopoietic cell transplant survivors in theUnited states. Biol Blood Marrow Transplant. 2013; 19:1498-501.

6. Bhatia S, Armenian SH, Landier W. How I monitor long-term and late effects after blood or marrow transplantation. Blood. 2017;130:1302-14.

7. Majhail NS. Long-term complications after hematopoietic cell transplantation. Hematol Oncol Stem Cell Ther. 2017;10:220-7.

8. Danylesko I, Shimoni A. Second malignancies after hematopoietic stem cell transplantation. Curr Treat Options in Oncol. 2018;19:9.

9. Sun $\mathrm{CL}$, Kersey JH, Francisco L, et al. Burden of morbidity in $10+$ year survivors of hematopoietic cell transplantation: report from the bone marrow transplantation survivor study. Biol Blood Marrow Transplant. 2013; 19:1073-80.

10. Brown JR, Yeckes $H$, Friedberg JW, et al. Increasing incidence of late second malignancies after conditioning with cyclophosphamide and total-body irradiation and autologous bone marrow transplantation for non-Hodgkin's lymphoma. J Clin Oncol. 2005;23:2208-14.

11. Leisenring W, Friedman DL, Flowers ME, et al. Nonmelanoma skin and mucosal cancers after hematopoietic cell transplantation. J Clin Oncol. 2006; 24:1119-26.

12. DePry JL, Vyas R, Lazarus HM, et al. Cutaneous malignant neoplasms in hematopoietic cell transplant recipients: a systematic review. JAMA Dermatol. 2015:151:775-82.

13. Kuklinski LF, Li S, Karagas MR, et al. Effect of voriconazole on risk of nonmelanoma skin cancer after hematopoietic cell transplantation. J Am Acad Dermatol. 2017;77:706-12.

14. Rambhia PH, Conic RZ, Atanaskova-Mesinkovska N, et al. Role of graftversus-host disease in the development of secondary skin cancers in hematopoietic stem cell transplant recipients: A meta-analysis. J Am Acad Dermatol. 2018;79:378-80 e3.

15. Sloand EM, Pfannes L, Ling C, et al. Graft-versus-host disease: role of inflammation in the development of chromosomal abnormalities of keratinocytes. Biol Blood Marrow Transplant. 2010;16:1665-73.

16. Omland SH, Gniadecki R, Haedersdal M, et al. Skin Cancer risk in hematopoietic stem-cell transplant recipients compared with background population and renal transplant recipients: a population-based cohort study. JAMA Dermatol. 2016;152:177-83.

17. Hasegawa W, Pond GR, Rifkind JT, et al. Long-term follow-up of secondary malignancies in adults after allogeneic bone marrow transplantation. Bone Marrow Transplant. 2005;35:51-5.

18. Curtis RE, Metayer C, Rizzo JD, et al. Impact of chronic GVHD therapy on the development of squamous-cell cancers after hematopoietic stem-cell transplantation: an international case-control study. Blood. 2005;105:3802-11.

19. Rigel DS, Russak J, Friedman R. The evolution of melanoma diagnosis: 25 years beyond the ABCDs. CA Cancer J Clin. 2010;60:301-16.

20. Berwick $M$, Begg CB, Fine JA, et al. Screening for cutaneous melanoma by skin self-examination. J Natl Cancer Inst. 1996;88:17-23.

21. Aitken JF, Elwood M, Baade PD, et al. Clinical whole-body skin examination reduces the incidence of thick melanomas. Int J Cancer. 2010;126:450-8.

22. Katalinic A, Waldmann A, Weinstock MA, et al. Does skin cancer screening save lives?: an observational study comparing trends in melanoma mortality in regions with and without screening. Cancer. 2012;118:5395-402.

23. Hahn T, Paplham P, Austin-Ketch T, et al. Ascertainment of unmet needs and participation in health maintenance and screening of adult hematopoietic cell transplantation survivors followed in a formal survivorship program. Biol Blood Marrow Transplant. 2017;23:1968-73.

24. Majhail NS, Rizzo JD, Lee SJ, et al. Recommended screening and preventive practices for long-term survivors after hematopoietic cell transplantation. Biol Blood Marrow Transplant. 2012;18:348-71.

25. Morton LM, Saber W, Baker KS, et al. National Institutes of Health hematopoietic cell transplantation late effects initiative: the subsequent neoplasms working group report. Biol Blood Marrow Transplant. 2017;23:367-78.
26. Shankar SM, Carter A, Sun CL, et al. Health care utilization by adult long term survivors of hematopoietic cell transplant: report from the bone marrow transplant survivor study. Cancer Epidemiol Biomark Prev. 2007;16: 834-9.

27. Prasad PK, Sun CL, Baker KS, et al. Health care utilization by adult Hispanic long-term survivors of hematopoietic stem cell transplantation: report from the bone marrow transplant survivor study. Cancer. 2008;113:2724-33.

28. Weinstock MA, Ferris LK, Saul Ml, et al. Downstream consequences of melanoma screening in a community practice setting: first results. Cancer. 2016:122:3152-6.

29. Koh HK, Miller DR, Geller AC, et al. Who discovers melanoma? Patterns from a population-based survey. J Am Acad Dermatol. 1992;26:914-9.

30. Geller AC, Emmons K, Brooks DR, et al. Skin cancer prevention and detection practices among siblings of patients with melanoma. J Am Acad Dermatol. 2003:49:631-8.

31. Daniel $\mathrm{CL}$, Armstrong GT, Keske RR, et al. Advancing Survivors' knowledge (ASK) about skin cancer study: study protocol for a randomized controlled trial. Trials. 2015;16:109.

32. Bruce AF, Mallow JA, Theeke LA. The use of teledermoscopy in the accurate identification of cancerous skin lesions in the adult population: a systematic review. J Telemed Telecare. 2018:24:75-83.

33. Pew Internet and Technology. 2018. http:/www.pewinternet.org/fact-sheet/ mobile/. Accessed 19 June 2019.

34. Pena-Robichaux V, Kvedar JC, Watson AJ. Text messages as a reminder aid and educational tool in adults and adolescents with atopic dermatitis: a pilot study. Dermatol Res Pract. 2010;2010.

35. Youl PH, Soyer HP, Baade PD, et al. Can skin cancer prevention and early detection be improved via mobile phone text messaging? A randomised, attention control trial. Prev Med. 2015;71:50-6.

36. Armstrong AW, Watson AJ, Makredes $M$, et al. Text-message reminders to improve sunscreen use: a randomized, controlled trial using electronic monitoring. Arch Dermatol. 2009:145:1230-6.

37. Oeffinger KC, McCabe MS. Models for delivering survivorship care. J Clin Oncol. 2006:24:5117-24.

38. Susong JR, Ahrns HT, Daugherty A, et al. Evaluation of a virtual dermatology curriculum for dermoscopy using the triage amalgamated Dermoscopic algorithm (TADA) for novice dermoscopists. J Am Acad Dermatol. 2019; (In Press).

39. Shaikh WR, Geller A, Alexander G, et al. Developing an interactive webbased learning program on skin cancer: the learning experiences of clinical educators. J Cancer Educ. 2012;27:709-16.

40. Hibbard JH, Stockard J, Mahoney ER, et al. Development of the patient activation measure (PAM): conceptualizing and measuring activation in patients and consumers. Health Serv Res. 2004;39:1005-26.

41. Hibbard JH, Mahoney E. Toward a theory of patient and consumer activation. Patient Educ Couns. 2010:78:377-81.

42. Mehrotra A, Hussey PS, Milstein A, et al. Consumers' and providers' responses to public cost reports, and how to raise the likelihood of achieving desired results. Health Aff (Millwood). 2012;31:843-51.

43. Rask KJ, Ziemer DC, Kohler SA, et al. Patient activation is associated with healthy behaviors and ease in managing diabetes in an indigent population. Diabetes Educ. 2009;35:622-30.

44. Cooper LA, Roter DL, Carson KA, et al. A randomized trial to improve patient-centered care and hypertension control in underserved primary care patients. J Gen Intern Med. 2011;26:1297-304.

45. Holman $\mathrm{H}$, Lorig K. Patient self-management: a key to effectiveness and efficiency in care of chronic disease. Public Health Rep. 2004;119:239-43.

46. Geller AC, O'Riordan DL, Oliveria SA, et al. Overcoming obstacles to skin cancer examinations and prevention counseling for high-risk patients: results of a national survey of primary care physicians. J Am Board Fam Pract. 2004:17:416-23.

47. Hibbard J, Lorig K. The dos and don'ts of patient engagement in busy office practices. J Ambul Care Manage. 2012:35:129-32.

48. Renders CM, Valk GD, de Sonnaville JJ, et al. Quality of care for patients with type 2 diabetes mellitus--a long-term comparison of two quality improvement programmes in the Netherlands. Diabet Med. 2003;20:846-52.

49. Jones $C$, Roderick $P$, Harris $S$, et al. An evaluation of a shared primary and secondary care nephrology service for managing patients with moderate to advanced CKD. Am J Kidney Dis. 2006:47:103-14.

50. Holm T, Lassen JF, Husted SE, et al. A randomized controlled trial of shared care versus routine care for patients receiving oral anticoagulant therapy. J Intern Med. 2002;252:322-31. 
51. Tsang MW, Resneck JS Jr. Even patients with changing moles face long dermatology appointment wait-times: a study of simulated patient calls to dermatologists. J Am Acad Dermatol. 2006;55:54-8.

52. Reiter $\mathrm{O}$, Mimouni I, Gdalevich $\mathrm{M}$, et al. The diagnostic accuracy of dermoscopy for basal cell carcinoma: a systematic review and meta-analysis. J Am Acad Dermatol. 2019;80:1380-8.

53. Yim KM, Florek AG, Oh DH, McKoy K, Armstrong AW. Teledermatology in the United States: An Update in a Dynamic Era. Telemed J E Health. 2018; 24:691-7.

54. Weinstock MA, Martin RA, Risica PM, et al. Thorough skin examination for the early detection of melanoma. Am J Prev Med. 1999;17:169-75.

55. Weinstock MA, Risica PM, Martin RA, et al. Melanoma early detection with thorough skin self-examination: the "check it out" randomized trial. Am J Prev Med. 2007;32:517-24.

56. Weinstock MA, Risica PM, Martin RA, et al. Reliability of assessment and circumstances of performance of thorough skin self-examination for the early detection of melanoma in the check-it-out project. Prev Med. 2004;38: $761-5$.

57. Swetter SM, Chang J, Shaub AR, et al. Primary care-based skin Cancer screening in a veterans affairs health care system. JAMA Dermatol. 2017;153: 797-801.

58. Gellar, Alan C. "Advancing Survivors' Knowledge (ASK) about skin cancer study: study protocol for a randomized controlled trial." Presentation, 2018 Emerging Technology in Childhood Cancer Survivorship Research Conference. Houston; 2018

59. Solomon JA, Oswalt M, Nodzenski M, et al. Assessing skin biopsy rates for histologic findings indicative of nonpathological cutaneous disease. Dermatol Surg. 2019;45:640-9.

60. Stang A, Jockel KH, Heidinger O. Skin cancer rates in North RhineWestphalia, Germany before and after the introduction of the nationwide skin cancer screening program (2000-2015). Eur J Epidemiol. 2018;33:303-12.

61. Hsiao WC, Braun P, Dunn DL, et al. An overview of the development and refinement of the resource-based relative value scale. The foundation for reform of U.S. physician payment. Med Care. 1992;30:NS1-12.

62. Drummond MF, Sculpher MJ, Torrance GW, et al. Methods for the Economic Evaluation of Health Care Programmes. (ed 3). New York: Oxford University Press; 2005.

\section{Publisher's Note}

Springer Nature remains neutral with regard to jurisdictional claims in published maps and institutional affiliations.

Ready to submit your research? Choose BMC and benefit from:

- fast, convenient online submission

- thorough peer review by experienced researchers in your field

- rapid publication on acceptance

- support for research data, including large and complex data types

- gold Open Access which fosters wider collaboration and increased citations

- maximum visibility for your research: over $100 \mathrm{M}$ website views per year

At $\mathrm{BMC}$, research is always in progress.

Learn more biomedcentral.com/submissions 